\title{
EDITORIAL
}

\section{Professional medical societies: do we have any conflict of interest with industry?}

\author{
Massimo Antonelli ${ }^{*}$ (D) and Craig M. Coopersmith ${ }^{2}$
}

(0) 2018 Springer-Verlag GmbH Germany, part of Springer Nature and ESICM

Conflicts of interest (COIs) have always occurred in scientific research and medical education. During the 1980s, the relationships between industry and academia intensified because of innovation and growth in biotechnology, pharmaceuticals and therapy. Industry currently funds nearly $60 \%$ of all biomedical research performed in the USA with pharmaceutical companies providing 30\%, biotechnology firms another $20 \%$ and medical device companies about $10 \%$. In 2004, these investments accounted for more than $50 \%$ of the clinical research being conducted in the USA [1]. Recently, there have been concerns about industry supporting an even larger component of research funding during times of contraction of federal government spending on research [2]. While recent increases in funding from the National Institutes of Health has mitigated these concerns, industry continues to fund the majority of nonbasic science. Defining COI policies that satisfy multiple stakeholders remains challenging.

When medical societies collaborate with companies to promote education or to develop products that improve health, in principle there is a benefit, but there are concerns that wide-ranging financial relationships to industry may inappropriately influence professional judgments. There are multiple potential domains in which COIs could potentially exist in interactions with industry.

Medical societies have partnered with industry to fund research fellowships, and COI concerns have called these into serious question, similar to universities acquiring partial industry funding for new academic positions [3, 4]. In addition, some databases sponsored by medical societies that are freely accessible to its membership are funded in part or completely by industry support [5]. Industry also supports medical journals through advertisements, purchase of articles and occasionally by supporting supplemental issues. This can be especially complicated for supplements funded by a single company and dealing with one drug [6].

Another major task of medical societies is the development of guidelines, where the possibility for $\mathrm{COI}$ is both direct and indirect. Guidelines can be directly supported by industry wherein a financial gift is given specifically to support their development, albeit without editorial control or representation on the guideline writing committee. Alternatively, guidelines may have indirect support from industry by virtue of the fact that panel members have benefited from research support and/or payment of activities on advisory boards or as consultants [7].

Medical societies represent the "public face" of their specialty and profession. Any situation that potentially compromises clinical decision making, negatively affects health care delivery or undermines the reputation of the profession is detrimental $[8,9]$. As such, medical societies have ethical obligations to their members, to patients and to society as a whole. Each medical society should

*Correspondence: massimo.antonelli@unicatt.it; massimo.antonelli@ policlinicogemelli.it

1 Department of Intensive Care Medicine, Anesthesiology and Emergency

Medicine, Fondazione Policlicnico Universitario A. Gemelli IRCCS-

Università Cattolica del Sacro Cuore, Largo Agostino Gemelli 8,

00168 Rome, Italy

Full author information is available at the end of the article

\section{实


function as an extension of its members, and all its leaders must be subject to commonly agreed upon professional norms. These norms involve meeting certain obligations, including the responsibility to gain and use medical knowledge with integrity, in the best interest of the patient and possibly limiting the self-serving interest [10-12]. Further, it is the duty of medical societies to provide unbiased education and services to members and patients. By the education provided, the practice guidelines endorsed and the ethical norms embraced by the medical society, the practice of medicine must be enhanced and optimized.

There are disparate views on how medical societies should interact with industry and what constitutes COI. The potential for unintended consequences due to medical society-industry relationships can therefore be quite challenging for professional organizations.

For example, at most annual meetings, industry has banners, booths and sponsored symposia. This visibility can be perceived as endorsement [13]. While there are inherent benefits to a relationship between a medical society and an industry partner, the medical society must carefully consider $\mathrm{COI}$ on a wide range of issues ranging from sponsorship to how to address industry symposia held in close proximity to the annual meeting.

While ideally a formal process for dealing with COI exists at each medical society (Table 1), unfortunately, a lack of structured regulatory systems within many medical societies is common. For example, a recent study by a group of Italian investigators from the Departments of Public Health and Biomedical Science reported that the industry sponsorship of Italian medical societies' conferences is common, with a substantial paucity of regulatory systems and scarce disclosure of the amount of industry funding (only $6 \%$ of all the societies shared information of their financing) [14].

Solutions to COI issues are complex and multifactorial. The days of wholly unregulated industry input are best left to history. However, some proposed solutions to entirely eliminate all industry presence seem fairly drastic and counterproductive. We believe a middle ground is the best way forward, in which a transparent and regulated process allows industry to financially support medical conferences, without which the dissemination and exchange of medical information might be limited.

COI solutions are also critical to guideline development. As an example of the complexities in this setting, the Surviving Sepsis Campaign international guidelines for sepsis management are produced by a collaboration between the European Society of Intensive Care Medicine and the Society Critical Care Medicine, and representatives from 20 different international medical societies formally participated in the development of the guidelines. Based upon this, the organizers in the last decade developed a rigorous and stringent COI policy [15]. No industry input into guidelines occurred, and no industry representatives were present at any meetings. Further, no member of the committee received financial compensation for their time on the committee. COI disclosure was made by each participant, which was then adjudicated by the Surviving Sepsis co-chairs, group heads and COI chair. Both financial and non-financial disclosures were submitted, of which 15 required a management plan limiting discussion or voting during which

Table 1 Basic principles for "interaction"

\begin{tabular}{|c|c|c|}
\hline & Independence & $\begin{array}{l}\text { All societal activities will be free of company influence, and all societal/industry interactions will be guided } \\
\text { by a high-level group (e.g., ethics committee, conflict of interest committee) }\end{array}$ \\
\hline 2. & Transparency & $\begin{array}{l}\text { The Society conflict of interest policies/forms are made available to the members and public, and com- } \\
\text { pany support is disclosed }\end{array}$ \\
\hline 3. & $\begin{array}{l}\text { Acceptance of charitable contribu- } \\
\text { tions }\end{array}$ & $\begin{array}{l}\text { This is appropriate if it aligns with the Societal mission and is free of company influence. In addition, poli- } \\
\text { cies for consistent and appropriate recognition of donors are to be adopted }\end{array}$ \\
\hline 4. & Acceptance of corporate sponsorship & $\begin{array}{l}\text { Only if it aligns with the Society mission. Reasonable efforts to seek multiple sponsors and not allow } \\
\text { company logos on "gifts" }\end{array}$ \\
\hline 5. & Full control of the Societal meetings & $\begin{array}{l}\text { The Society must have full control over the entire program from topics to speaker selection, allowing } \\
\text { presentation of a balanced educational program addressing areas of knowledge gaps. The Society itself } \\
\text { will address any COI issues }\end{array}$ \\
\hline 6. & Awarding of research grants & $\begin{array}{l}\text { Independence is critical in that aspect, and companies cannot influence the selection of recipients, receive } \\
\text { intellectual property rights or royalties resulting from the research or influence the results or manuscripts } \\
\text { resulting from the research. Societal research supported by corporate funding requires disclosure and } \\
\text { independence of all aspects of the research }\end{array}$ \\
\hline & Clinical practice guidelines & $\begin{array}{l}\text { They must be evidence-based, free of company influence and not directly supported by companies } \\
\text { during any phases of development or publication. Panel members and chairs must be free of conflict } \\
\text { of interest relevant to the guideline and publication. The entire process must be completely devoid of } \\
\text { corporate influence at all levels }\end{array}$ \\
\hline & Societal journals & $\begin{array}{l}\text { Publications must have editorial independence from the Society and must be free from any potential } \\
\text { influence from companies }\end{array}$ \\
\hline
\end{tabular}


content relevant to their COI was discussed. In addition, five members were reassigned to a different work group because of COI while one individual was asked to step down from the committee.

From a global perspective, ALLEA (All European Academies), the European Federation of Academies of Sciences and Humanities and United States National Academy of Sciences have provided guidance for transparency of research and relationships among medical societies, researchers and industry based upon the principles of Reliability, Honesty, Respect and Accountability [16, 17]. In addition, the Council of Medical Specialty Societies has published a voluntary "Code of Interactions with the For-Profit Health Sector," which directly addresses COI policies for medical societies, and many American medical societies have formally adapted the code with commitment to full implementation [18].

\section{Conclusions}

The interaction between medical societies and industry has the potential for great benefit, but also runs the risk of significant COI. Industry funds $30-50 \%$ or more of many professional medical associations by supporting their annual meetings. Since the medical society is the public face of our profession and directs professional decisions and activities regarding education, publications and practice guidelines, the issue of COI remains a real concern for members, patients and affiliated organizations. Since public trust and the medical society's integrity are ethical fundaments, any real or perceived situation that could put into question the society's duty to the public interest and well-being is unacceptable. As a result, formal methods to manage or divest COI with industry must be part of the inner working of each medical society to allow pursuing its core mission free of industry influence while allowing for society-industry partnerships based upon the principles of Honesty, Transparency, Reliability, Respect and Accountability.

\footnotetext{
Author details

${ }^{1}$ Department of Intensive Care Medicine, Anesthesiology and Emergency Medicine, Fondazione Policlicnico Universitario A. Gemelli IRCCS-Università Cattolica del Sacro Cuore, Largo Agostino Gemelli 8, 00168 Rome, Italy. 2 Department of Surgery and Emory Critical Care Center, Emory University School of Medicine, Atlanta, GA, USA.
}

\section{Compliance with ethical standards}

\section{Conflicts of interest}

The authors declare no conflict of interest with the content of the present manuscript.
Received: 27 June 2018 Accepted: 4 July 2018

Published online: 13 July 2018

References

1. Moses H, Dorsey ER, Matheson DH, Their SO (2005) Financial anatomy of biomedical research. JAMA 294:1333-1342

2. Hampton $T$ (2006) Health research funding losing ground. JAMA 296:1219-1220

3. Lichter PR (2008) Debunking myths in physician-industry conflicts of interest. Am J Ophthalmol 146:159-171

4. Kuehn BM (2005) Pharmaceutical industry funding for residencies sparks controversy. JAMA 293:1572-1580

5. American Venous Forum, Venous Registry. http://veinforum.org/index php?page=venous-registry. Accessed 20 Jun 2018

6. Smith R (2003) Medical journals and pharmaceutical companies: uneasy bedfellows. BMJ 326:1202-1205

7. Steinbrook R (2007) Guidance for guidelines. N Engl J Med 356:331-333

8. Rothman DJ, McDonald WJ, Berkowitz CD, Chimonas SC, DeAngelis CD, Hale RW et al (2009) Professional medical associations and their relationships with industry: a proposal for controlling conflict of interest. JAMA 301(1367-13723):31

9. Kassirer JP (2007) Professional societies and industry support: what is the quid pro quo? Perspect Biol Med 50:7-17

10. Cruess SR (2006) Professionalism and medicine's social contract with society. Clin Orthop Relat Res 449:170-176

11. Foundation ABIM (2002) ACP-ASIM Foundation, American College of Physicians-American Society of Internal Medicine, European Federation of Internal Medicine Medical professionalism in the new millennium: a physician charter. Ann Intern Med 136:243-246

12. Bloche MG (1999) Clinical loyalties and the social purposes of medicine. JAMA 281:268-274

13. Camilleri M, Parke DW (2010) Perspective: conflict of interest and professional organizations: considerations and recommendations. Acad Med 85:85-91

14. Fabbri A, Gregoraci G, Tedesco D, Ferretti F, Gilardi F, lemmi D, Lisi C, Lorusso A, Natali F, Shahi E, Rinaldi A (2016) Conflict of interest between professional medical societies and industry: a cross-sectional study of Italian medical societies' websites. BMJ Open 6(6):e011124. https://doi. org/10.1136/bmjopen-2016-011124

15. Rhodes A, Evans LE, Alhazzani W, Levy MM, Antonelli M, Ferrer R, Kumar A, Sevransky JE, Sprung CL, Nunnally ME, Rochwerg B, Rubenfeld GD, Angus DC, Annane D, Beale RJ, Bellinghan GJ, Bernard GR, Chiche JD, Coopersmith C, De Backer DP, French CJ, Fujishima S, Gerlach H, Hidalgo JL, Hollenberg SM, Jones AE, Karnad DR, Kleinpell RM, Koh Y, Lisboa TC, Machado FR, Marini JJ, Marshall JC, Mazuski JE, McIntyre LA, McLean AS, Mehta S, Moreno RP, Myburgh J, Navalesi P, Nishida O, Osborn TM, Perner A, Plunkett CM, Ranieri M, Schorr CA, Seckel MA, Seymour CW, Shieh L, Shukri KA, Simpson SQ, Singer M, Thompson BT, Townsend SR, Van der Poll T, Vincent JL, Wiersinga WJ, Zimmerman JL, Dellinger RP (2017) Surviving sepsis campaign: international guidelines for management of sepsis and septic shock: 2016. Intensive Care Med 43(3):304-377. https:// doi.org/10.1007/s00134-017-4683-6 Epub 2017 Jan 18

16. Lo B, Field MJ (eds) (2009) Conflict of interest in medical research, education, and practice. Institute of Medicine (US) Committee on Conflict of Interest in Medical Research, Education, and Practice. National Academies Press (US), Washington (DC). ISBN-13: 978-0-309-13188-9

17. The European Code of Conduct for Research Integrity. https://ec.europ a.eu/research/participants/data/ref/h2020/other/hi/h2020-ethics_codeof-conduct_en.pdf

18. Council of Medical Specialty Societies Press release. https://cmss.org/wpcontent/uploads/2016/02/CMSS-Code-for-Interactions-with-CompaniesApproved-Revised-Version-4.13.15-with-Annotations.pdf. Accessed Jun 2018 